\title{
Expression pattern of Wif1 and $\beta$-catenin during development of anorectum in fetal rats with anorectal malformations
}

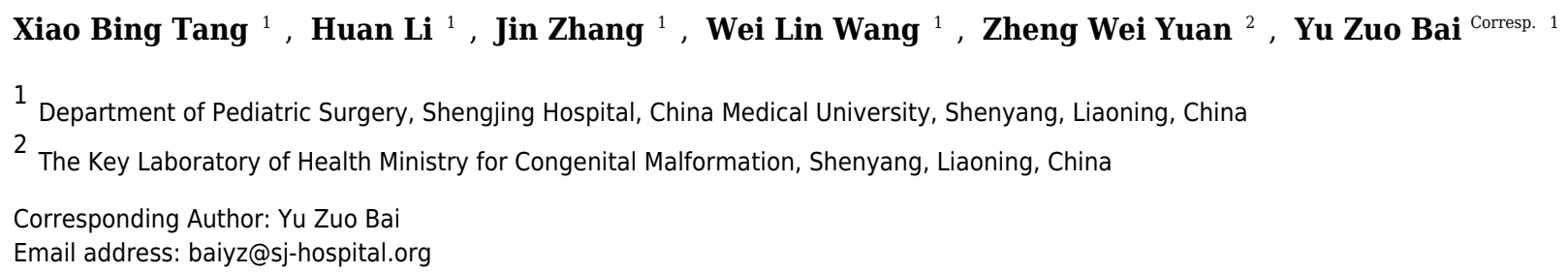

Purpose: This study was performed to investigate the expression pattern of Wnt inhibitory factor 1 (Wif1) and $\beta$-catenin during anorectal development in normal and anorectal malformation (ARM) embryos and the possible role of Wif1 and $\beta$-catenin in the pathogenesis of ARM. Methods: ARM was induced with ethylenethiourea on the 10th gestational day in rat embryos. Cesarean deliveries were performed to harvest the embryos. The expression pattern of Wif1 and $\beta$-catenin protein and mRNA was evaluated in normal rat embryos $(n=288)$ and ARM rat embryos $(n=306)$ from GD13 to GD16 using immunohistochemical staining, Western blot, and real time RT-PCR. Results: Immunohistochemical staining revealed that in normal embryos Wif1 was constantly expressed in the cloaca from GD13 to GD16. On GD13 and GD14, Wif1-immunopositive cells were extensively expressed in the cloaca. On GD15, the expression of Wif1 were mainly detected on the very thin anal membrane. In ARM embryos, the epithelium of the hindgut and urorectal septum demonstrated faint immunostaining for Wif1 from GD14 to GD16. Western blot and real time RT-PCR revealed that Wif1 and $\beta$-catenin protein and mRNA expression level was significantly decreased in the ARM groups compared with the normal group on GD14 and GD15 ( $p<0.05)$. Conclusions: This study demonstrated that the expression pattern of Wif1 and $\beta$-catenin was disrupted in ARM embryos during anorectal morphogenesis, which demonstrated that downregulation of Wif1 and $\beta$-catenin at the time of cloacal separation into the primitive rectum and urogenital septum might related to the development of ARM. 
1 Expression pattern of Wifl and $\beta$-catenin during development of anorectum in fetal rats with anorectal malformations

3 Xiao Bing Tang ${ }^{1}$, Huan $\mathrm{Li}^{1}$, Jin Zhang ${ }^{1}$, Wei Lin Wang ${ }^{1}$, Zheng Wei Yuan ${ }^{2}$, Yu Zuo Bai ${ }^{1}$

5 1. Department of Pediatric Surgery, Shengjing Hospital, China Medical University, Shenyang 110004, PR

6 China

7 2. The Key Laboratory of Health Ministry for Congenital Malformation, Shenyang 110004, PR China

9 Correspondence to: Professor Yu Zuo Bai, Department of Pediatric

10 Surgery, Shengjing Hospital, China Medical University, No. 36

11 Sanhao Street, Heping District, Shenyang, P.R. China 110004.

12 Tel: 0086-24-9661557111; Fax: 0086-24-23892617

13 E-mail: baiyz@sj-hospital.org 
28 Abstract

29 Purpose: This study was performed to investigate the expression pattern of Wnt inhibitory factor 1 (Wifl) and

$30 \beta$-catenin during anorectal development in normal and anorectal malformation (ARM) embryos and the 31 possible role of Wif1 and $\beta$-catenin in the pathogenesis of ARM.

32 Methods: ARM was induced with ethylenethiourea on the 10th gestational day in rat embryos. Cesarean 33 deliveries were performed to harvest the embryos. The expression pattern of Wif1 and $\beta$-catenin protein and 34 mRNA was evaluated in normal rat embryos $(n=288)$ and ARM rat embryos $(n=306)$ from GD13 to GD16 35 using immunohistochemical staining, Western blot, and real time RT-PCR.

36 Results: Immunohistochemical staining revealed that in normal embryos Wif1 was constantly expressed in the 37 cloaca from GD13 to GD16. On GD13 and GD14, Wif1-immunopositive cells were extensively expressed in 38 the cloaca. On GD15, the expression of Wif1 were mainly detected on the very thin anal membrane. In ARM 39 embryos, the epithelium of the hindgut and urorectal septum demonstrated faint immunostaining for Wif1 from 40 GD14 to GD16. Western blot and real time RT-PCR revealed that Wifl and $\beta$-catenin protein and mRNA 41 expression level was significantly decreased in the ARM groups compared with the normal group on GD14 and $42 \operatorname{GD} 15(p<0.05)$.

43 Conclusions: This study demonstrated that the expression pattern of Wif1 and $\beta$-catenin was disrupted in ARM 44 embryos during anorectal morphogenesis, which demonstrated that downregulation of Wifl and $\beta$-catenin at 45 the time of cloacal separation into the primitive rectum and urogenital septum might related to the development 46 of ARM.

Introduction

49 Anorectal malformations (ARM) are very common surgical disorders frequently encountered in pediatric 50 surgery practice. The incidence is approximately 1 in 5000 live births. There is a wide spectrum of ARM 51 phenotypes, ranging from stenotic anus to cloacal malformation (Endo et al. 1999). Surgical operation is the

52 main modality of treatment. Although the level of ARM surgical treatment has improved, there are still

53 different degrees of complications, which seriously affect the quality of life (Peña et al. 1998; Peña et al. 2000;

54 Bai et al. 2000; Levitt et al. 2005; Rintala. 2016). Up to now, the etiology of ARMs is unknown. Genetic factors are important contributing factors in the pathogenesis of ARMs. Genetic signaling must be precisely 
57 member of the families of secreted molecules known to inhibit Wnt signalling activity. Wifl was first identified 58 as an expressed sequence tag from the human retina, and highly conserved orthologues have been isolated from 59 mouse, Xenopus and zebrafish (Hsieh et al. 1999). $\beta$-catenin is a critical component of canonical Wnt signaling 60 and is essential for the regulation of cell differentiation and morphogenesis during embryogenesis. The 61 presence of Wifl leads to $\beta$-catenin degradation, thereby turning off Wnt-bcatenin signaling (Kawano Y and Kypta R. 2003). Previous study has detected that Wifl expressed in the midline cloaca endoderm, and dysregulated Wifl expression caused septation defects. In Wifl ${ }^{\text {laczlacz }}$ mutant mice and cultured urorectum with exogenous Wif1, cloaca septation was defective with undescended urorectal septum (URS) and hypospadiaslike phenotypes (Ng et al. 2014). Both $\beta$-catenin loss- and gain-of-function (LOF and GOF) mutants displayed abnormal clefts in the perineal region and hypoplastic elongation of the URS (Miyagawa S et al. 2014). These results suggest that Wif1 and $\beta$-catenin is required for urorectal development. However, the expression pattern of Wif1 and $\beta$-catenin has not been described previously in the embryogenesis of rat ARMs. To provide an insight into the role of Wif1 and $\beta$-catenin in anorectal morphogenesis, we have analyzed the expression of Wif1 and $\beta$-catenin protein and mRNA in normal and ethylenethiourea (ETU)-induced ARM rat embryos on embryonic stages GD13 to GD16, a critical time in anorectal development.

\section{Materials and methods}

\section{Animal model and tissue collection}

Mature Wistar rats (body weights, 250-300g) were provided by the Medical Animal Center, Shengjing Hospital of the China Medical University (Shenyang, PR China). Ethical approval was obtained from the China Medical University Animal Ethics (no. 200(7) PS14) prior to the study. Procedures for generating ARMs in fetal rats are described in earlier study (Bai et al. 2004). 70 time-mated pregnant Wistar rats were randomly divided into two groups: ETU-treated group and normal group. In the ETU-treated group, 40 pregnant rats were gavage-fed a single dose of $125 \mathrm{mg} / \mathrm{kg}$ of $1 \%$ ETU (2-imidazolidinethione; CAS number: 96-45-7; Aldrich Chemical, Penzberg, Germany) on GD10 (GD0=sperm in vaginal smear after overnight mating). 30 normal rats received corresponding doses of ETU-free saline on GD10. Embryos were harvested by cesarean delivery from GD13 to GD16. One third of the embryos were fixed in 4\% paraformaldehyde for 12 to 24 hours depending on their size. Then the embryos from each age group were dehydrated, embedded in paraffin, and sectioned serially sagittally at $4-\mu \mathrm{m}$ thickness for immunohistochemical staining. The presence of ARMs was determined by light microscope. Then, the embryos were divided into normal and ARM groups. Under magnification, the 
86 cloaca/hindgut of the remaining two thirds of the embryos was dissected and removed from surrounding

87 tissues. The cloaca/hindgut was immediately frozen in liquid nitrogen for Western blot analysis and real-time

88 RT-PCR.

89 Immunohistochemical staining

90 The slides were treated and incubated with primary Anti-Wif1 (1:200 dilution, Rabbit polyclonal, ab186845,

91 UK) and horseradish peroxidase (HRP)-conjugated secondary antibody (Santa Cruz Bio-technology). Antibody

92 incubations were performed in phosphate-buffered saline (PBS) supplemented with 10\% goat serum.

93 Incubation with the secondary antibody was performed for $20 \mathrm{~min}$ at room temperature, and signals were

94 visualized by using 3 '3Pdiaminobenzidine (DAB; Sigma, UK). Two pathologists independently reviewed the

95 immunohistochemical stained slides and agreed on results by consensus.

96 (https://www.protocols.io/view/immunohistochemical-staining-kujcwun)

\section{Protein preparation and Western blot}

98 Protein preparation was performed as described previously (Mandhan et al. 2006a): the cloaca/hindgut per 99 condition were pooled and sonicated in $\mathrm{ddH} 2 \mathrm{O}$ containing protease inhibitors. Protein extracts were seperated 100 on SDS-PAGE electrophoresis, and transferred to PVDF membranes, blocked with 5\% fat-free milk in Tris-

101 buffered saline ( $2 \mathrm{hr}$, room temperature). Membrane were incubated in primary antibody against Wif1 (diluted 102 1:500, Rabbit polyclonal, ab186845, UK), $\beta$-catenin (diluted 1:1500, mouse monoclonal, BD Biosciences, 103 cat\#610154, USA) or anti- $\beta$-Actin rabbit monoclonal antibody (1:2000 dilution; Sigma, St Louis, MO, USA), 104 and incubated with the secondary antibody (diluted 1:3000, goat anti-rabbit or goat anti-mouse HRP conjugate;

105 Jackson Immunoresearch, West Grove, Pa., USA). Membranes were developed by using a chemiluminescent 106 substrate kit (Pierce, Pierce, Rockford, Ill., USA) and densitometric values were analyzed by using the ECL

107 Plus detection system (Millipore, Billerica, Mass., USA).

108 (https://www.protocols.io/view/western-blot-analysis-kumcwu6)改

109 RNA Isolation and Real-Time RT-PCR

110 Total RNA was isolated with the TRIzol reagent (Invitrogen) according to the manufacturer's protocol. RNA

$111(1 \mu \mathrm{g})$ was reverse transcribed by using the Prime Script RT reagent kit (TaKaRa) following the manufacturer's 112 instructions. Quantitative real-time RT-PCR was accomplished with SYBR Premix Ex Tap (TaKaRa) on the $1137900 \mathrm{HT}$ fast real-time PCR system (Applied Biosystems) under the following conditions: $50^{\circ} \mathrm{C}$ for $2 \mathrm{~min}, 95^{\circ} \mathrm{C}$ 114 for $10 \mathrm{~min}, 40$ cycles of $95^{\circ} \mathrm{C}$ for $15 \mathrm{~s}, 60^{\circ} \mathrm{C}$ for $60 \mathrm{~s}$. A dissociation procedure was performed to generate a 
115 melting curve for confirmation of amplification specificity. GAPDH was used as the reference gene as reported

116 previously (Mandhan et al. 2006b; Tang et al. 2014a; Tang et al. 2014b). The relative levels of gene

117 expression were represented as $\Delta \mathrm{Ct}=\mathrm{Ct}$ gene- $\mathrm{Ct}$ reference, and the fold-change of gene expression were

118 calculated with the $2^{-\Delta \Delta C t}$ method. Experiments were repeated in triplicate. The primer sequences spanning the

119 intron-exon junction were as follows:

120 Wifl forward: 5'-AGCCATTCCCGTCAATATCCAC-3';

121 reverse: 5'-TGCCATGATGCCTTTATCCAG-3'.

$122 \quad \beta$-catenin forward: 5'-CGCTTGGCTGAACCGTCACA-3';

123 reverse:5'-TGGTCCTCGTCATTTAGCAGT-3'.

124 GAPDH forward: 5'-GCTGGTCATCAACGGGAAA-3';

125 reverse:5' -CGCCAGTAGACTCCACGACAT-3 ' .

\section{Statistical Analysis}

127 The Statistical Program for Social Sciences, version 13.0 (SPSS, Chicago, III) was used for statistical

128 analysis. The two-way ANOVA with Post-hoc test was used to compare the Wif1 and $\beta$-catenin protein and 129 mRNA levels between the ARM and normal groups. All numerical data were presented a mean \pm standard 130 deviation. A value of $p<0.05$ was considered statistical significance.

Results

132 General observations

133 In this study, no malformations were observed in the 288 embryos of the normal rats. Among the ETU-

134 treated embryos, all 378 embryos had short or no tail and 19 of embryos died in utero. The incidence of ARMs

135 in ETU-treated embryos was 81.0\% (306/378). The embryos for immunohistochemistry staining, Western blot,

136 and real time RT-PCR in each group are shown in Table 1. The type of ARMs was persistent cloaca or

137 rectourethral fistula.X

138 ᄃ Immunohistochemical staining

139 Normal group

140 On GD13, the cloaca was divided into urogenital sinus (UGS) ventrally and primitive hindgut dorsally by the

141 L-shaped URS. Wifl-immunopositive cells were extensively expressed on the epithelium and mesenchyme of 142 the cloaca (Fig. 1a, b).

143 On GD14, a potential cana located between the tip of the URS and the cloacal membrane (CM). Wif1-

144 immunopositive cells were detected on the hindgut, URS, urethra and CM (Fig. 2a, b). 
145 On GD15, the epithelium on the tip of the URS fused with the dorsal CM, leading to separation of the hindgut

146 and UGS. The anal membrane (AM) was nearly ruptured. Wifl-immunopositive cells were mainly detected on

147 the very thin AM (Fig. 3a, b).

148 On GD16, the AM ruptured and the rectum separated from the UGS completely. The anorectum 149 communicated with the outside. Wifl-immunolabeled cells were observed on the epithelium of the distal 150 anorectum (Fig. 4a, b).

151 ARM group

152 On GD13, comparing with normal embryos, the distance between the URS and the CM was long, and the CM 153 was shorter and thicker. Wifl-labeled cells were extensively expressed on the epithelium and mesenchyme of 154 the cloaca (Fig. 1c, d).

155 On GD14, the URS was high in the cloacal cavity, and the distance between URS and CM was relatively long. 156 Wif1 was faintly expressed on the epithelium of the hindgut, URS and the urethra (Fig. 2c, d).

157 On GD15, the distance between the URS and CM shortened, but the URS did not fused with the CM. The

158 fistula between the rectum and urethra was evident, and the hindgut did not separate from UGS. Positive cells 159 were sparsely located on the epithelium of the hindgut, fistula and the urethra (Fig. 3c, d).

160 On GD16, the fistula between the rectum and urethra was existing, and rectal terminus was still not opened to 161 the outside. Wifl demonstrated low expression on the epithelium of the rectum, fistula and the urethra (Fig. 4c, 162 d).

163 Western blot analysis

164 Western blot specific for Wif1 was performed to quantify protein expression in the anorectal development 165 (From GD13 to GD16: Wif1 protein $1.03 \pm 0.02$ vs $0.94 \pm 0.04,1.17 \pm 0.08$ vs $0.99 \pm 0.05,1.07 \pm$ 1660.04 vs $0.91 \pm 0.05,0.96 \pm 0.07$ vs $0.90 \pm 0.03 ; \beta$-catenin protein $0.98 \pm 0.05$ vs $0.88 \pm 0.02,1.14 \pm$ 1670.04 vs $1.01 \pm 0.05,1.09 \pm 0.01$ vs $1.00 \pm 0.05,0.87 \pm 0.02$ vs $0.85 \pm 0.01)$ (Fig. 5). Wif1 and $\beta$ 168 catenin was detected as bands of approximately $41 \mathrm{kDa}$ and $95 \mathrm{kDa}$ respectively among the proteins extracted 169 from normal and ARM tissue. Each protein band was normalized to a corresponding $\beta$-Actin band. On GD14 170 and GD15, the key periods of anus formation, Wif1 expression reached high levels in the normal group but was 171 relatively low in the ARM group $(p<0.05)$.

\section{Real-time RT-PCR}

173 Wifl and $\beta$-catenin mRNA expression was calculated in the normal and ARM groups (From GD13 to 
174 GD16: Wifl mRNA 1 vs $0.78 \pm 0.24,1.29 \pm 0.24$ vs $0.89 \pm 0.07,1.26 \pm 0.23$ vs $0.88 \pm 0.03,1.12 \pm$

1750.17 vs $1.06 \pm 0.13 ; \beta$-catenin mRNA 1 vs $0.77 \pm 0.12,1.13 \pm 0.05$ vs $0.84 \pm 0.14,1.05 \pm 0.12$ vs

$1760.77 \pm 0.12,0.77 \pm 0.06$ vs $0.74 \pm 0.09)($ Fig. 6). On GD14 and GD15, Wif1 and $\beta$-catenin mRNA

177 expression reached the estimated optimum levels in the normal group. Wifl and $\beta$-catenin mRNA expression

178 was significantly decreased in the ARM hindgut compared with normal hindgut on GD14 and GD15 ( $p<0.05)$.

Discussion

180 ETU-induced ARMs in rat embryos has been previously employed to study the morphological changes of

181 ARMs by several groups, including our laboratory (Qi et al. 2002; Bai et al. 2004; Mandhan et al. 2006a;

182 Mandhan et al. 2006b; Zhang et al. 2009; Wang et al. 2009; Tang et al. 2014a; Tang et al. 2014b; Zhang et al.

183 2015)․ In this study, expression of Wifl in the anorectum showed differences in spatial distribution between

184 normal and ARM embryos. Fusion of URS with CM is a traditional theory in the development process of

185 anorectum (de Vries et al. 1974; Qi et al. 2002; Bai et al. 2004). If the URS does not merge with the CM, the

186 anorectum fails to separate from the urethra. A common canal between the rectum and urethra still exists,

187 which leads to the rectourethral fistula or persistent cloaca (types of ARM) . On GD15, Wif1-immunopositive

188 cells were selectively detected on the very thin AM (developed from the $\mathrm{CM}$ ) in normal embryos. In contrast,

189 only sporadic Wif1 immunostaining located on the epithelium of the hindgut, fistula and the urethra in ARM

190 embryos. Therefore, morphogenic events in the anorectum depend on Wifl signal induction, and Wifl might be

191 important for the development of the CM during embryogenesis of the anorectum. A recently study indicated

192 WIF-1 suppress the proliferation, invasion and metastasis of the GBC-SD cells and increases the apoptosis of

193 the GBC-SD cells (Huang Y et al. 2015). Lack of Wifl in CM may decrease the apoptosis of CM and

194 contribute to incompletely separation of the cloaca, thus contributing to the ARMs.

195 Wif1 and $\beta$-catenin expression shows time-dependent changes during anorectal development. Western blot

196 analysis and real time RT-PCR shown that, in the normal embryos, Wif1 and $\beta$-catenin expression was at its

197 highest level at the key time-point of anorectal development (GD14 and GD15), suggesting that it may play an

198 role in the development of the anorectum. However, Wif1 and $\beta$-catenin expression levels on GD14 and GD15

199 were significantly lower in the ARM group compared with the normal group, implying that downregulation of

200 Wifl and $\beta$-catenin expression during the critical period of anorectal development may contribute to the ARMs.

201 Additionally, when the anus opened on GD16, the expression of Wif1 and $\beta$-catenin protein decreased. This

202 suggest that Wif1 may play an essential role during initial morphogenesis of the anorectum, but its role during 
203 subsequent development of the anorectum may be less important.

204 Wifl is one member of Wnt antagonists, which bind to Wnt directly and inhibit the link with their

205 receptors, and as a result, the accumulation of $\beta$-catenin is reduced and canonal and noncanonal pathway are

206 inhibited (Malinauskas et al. 2011). $\mathrm{Ng}$ et al detected that Wifl expressed in the midline cloaca endoderm, and

207 dysregulated Wifl expression caused septation defects ( $\mathrm{Ng}$ et al. 2014). $\beta$-catenin LOF and GOF mutants both

208 displayed abnormal separation of the cloaca and maldevelopment of the URS (Miyagawa et al. 2014). $\beta$ -

209 catenin is a critical component of canonical Wnt signaling and is essential for the regulation of cell

210 differentiation and morphogenesis during embryogenesis. Dysregulation of Wif1- $\beta$-catenin signaling may

211 influence proliferation and apoptosis of CM and URS, and lead to maldevelopment of the anorectum, even

212 contributing to ARM.

213 ETU is known to disturb the expression of the shh signaling pathway during the development of the

214 hindgut (Mandhan et al. 2006a; Mandhan et al. 2006b). RC-L Ng had demonstrated that dysregulation of Shh-

215 Wif1-Wnt- $\beta$-catenin signaling contributes to ARMs using transgenic mice $(\mathrm{Ng}$ et al. 2014)ᄃ. Wif1 and $\beta$ -

216 catenin levels were reduced in ETU exposed embryos during hindgut development. $\beta$-catenin signaling is

217 required for caudal neural tube closure and elongation, acting through the transcriptional regulation of Cdx 2

218 (Zhao et al. 2014). $\beta$-catenin GOF mutants ectopically induces Bmp4 and Bmp7 expression in the epithelia of

219 the URS, and the ARM phenotypes in the $\beta$-catenin GOF mutants could be restored by additionally introducing

220 the Bmpr1A gene mutation. (Miyagawa et al. 2014). Previously studies showed that ETU disturbed the

221 expression of Cdx2, Bmp2, Bmpr1a, Bmp4, Bmp7 in anorectum of rat embryos ( Mandhan et al. 2006b; Tang

222 et al. 2014b; Tang et al. 2016; Zhang et al. 2015). All the above evidences indicate that ETU might disturb

223 the expression of $\mathrm{Cdx} 2$ and Bmp through Wif1- $\beta$-catenin signal pathway and lead to ARM in rat embryos.

$224 \mathrm{Cdx} 2$ and Bmp may function downstream of Wif1- $\beta$-catenin signal pathway during anorectal morphogenesis.

Conclusions

226 In summary, the expression pattern of Wifl and $\beta$-catenin was impaired during development of anorectum in

227 fetal rats with ETU-induced ARMs. This indicates that Wifl and $\beta$-catenin might play an important role in

228 morphogenesis of the anorectum. Decreased Wif1 and $\beta$-catenin expression might be related to the

229 development of ARMs. Further studies are needed to define the specific roles of Wif1 and $\beta$-catenin during

230 anorectal development, and thus improve our understanding of the pathogenesis of ARMs. 
244 References

245 Bai Y, Chen H, Yuan ZW, Wang W. 2004. Normal and abnormal embryonic development of the anorectum in 246 rats. Journal of Pediatric Surgery 39:587-590 DOI.10.1016/j.jpedsurg.2003.12.002.

247 Bai Y, Yuan Z, Wang W, Zhao Y, Wang H, Wang W. 2000. Quality of life for children with fecal incontinence 248 after surgically corrected anorectal malformation. Journal of Pediatric Surgery 35:462-464 DOI 249 10.1016/S0022-3468(00)90215-X.

250 de Vries PA, Friedland GW. 1974. The staged sequential development of the anus and rectum in human

251 embryos and fetuses. Journal of Pediatric Surgery 9:755-769 DOI 10.1016/0022-3468(74)90115-8.

252 Endo M, Hayashi A, Ishihara M Maie M, Nagasaki A, Nishi T, Saeki M. 1999. Analysis of 1,992 patients with 253 anorectal malformations over the past two decades in Japan. Steering Committee of Japanese Study Group of

254 Anorectal Anomalies. Journal of Pediatric Surgery 34:435-441

255 Huang Y, Du Q, Wu W, She F, Chen Y. 2016. Rescued expression of WIF-1 in gallbladder cancer inhibits

256 tumor growth and induces tumor cell apoptosis with altered expression of proteins. Molecular Medicine 257 Reports 14:2573-2581 DOI 10.3892/mmr.2016.5532.

258 Hsieh JC, Kodjabachian L, Rebbert ML, $\underline{\text { Rattner A, Smallwood PM, Samos CH, Nusse R, Dawid IB, Nathans }}$

259 J. 1999. A new secreted protein that binds to Wnt proteins and inhibits their activities. Nature 398:431-436

260 DOI $10.1038 / 18899$ 
261 Kawano Y, Kypta R. 2003. Secreted antagonists of the Wnt signalling pathway. Journal of Cell Science

262 116:2627-2634 DOI 10.1242/jcs.00623

263 Levitt MA, Peña A. 2005. Outcomes from the correction of anorectal malformations. Current Opinion in

264 Pediatrics 17:394-401 DOI 10.1097/01.mop.0000163665.36798.ac

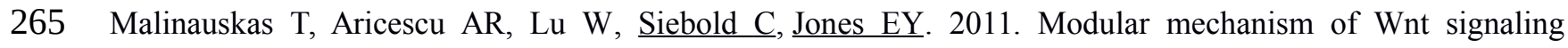

266 inhibition by Wnt inhibitory factor 1. Nature Structural \& Molecular Biology 18:886-893 DOI

$267 \quad 10.1038 / \mathrm{nsmb} .2081$

268 Mandhan P, Beasley S, Hale T, Ellmers L, Roake J, Sullivan M. 2006a. Sonic hedgehog expression in the

269 development of hindgut in ETU-exposed fetal rats. Pediatric Surgery International 22:31-36 DOI

$270 \quad 10.1007 / \mathrm{s} 00383-005-1575-6$

271 Mandhan P, Quan QB, Beasley S, Sullivan M. 2006b. Sonic hedgehog, BMP4, and Hox genes in the

272 development of anorectal malformations in Ethylenethiourea-exposed fetal rats. Journal of Pediatric Surgery

273 41:2041-2045 DOI 10.1016/j.jpedsurg.2006.08.035

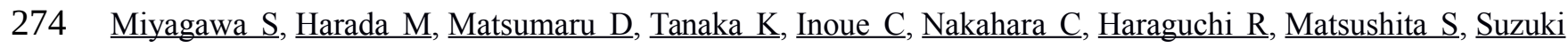

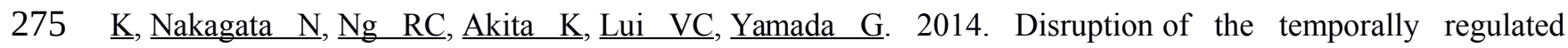
276 cloaca endodermal $\beta$-catenin signaling causes anorectal malformations. Cell Death and Differentiation 21:990-

277997 DOI 10.1038/cdd.2014.21

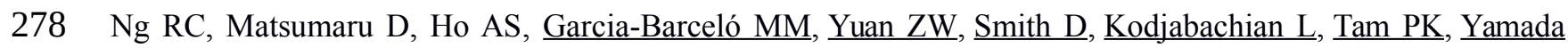

279 G, Lui VC. 2014. Dysregulation of Wnt inhibitory factor 1 (Wif1) expression resulted in aberrant Wnt- $\beta$ -

280 catenin signaling and cell death of the cloaca endoderm, and anorectal malformations. Cell Death and

281 Differentiation 21:978-989 DOI 10.1038/cdd.2014.20

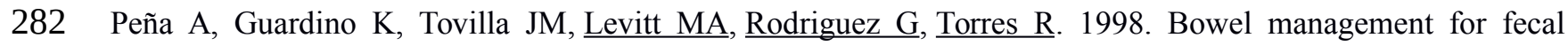

283 incontinence in patients with anorectal malformations. Journal of Pediatric Surgery 33:133-137 DOI

$284 \quad 10.1016 / \mathrm{S} 0022-3468(98) 90380-3$

285 Peña A, Hong A. 2000. Advances in the management of anorectal malformations. The American Journal of

286 Surgery 180:370-376 DOI 10.1016/S0002-9610(00)00491-8

287 Qi BQ, Beasley SW, Frizelle FA. 2002. Clarification of the processes that lead to anorectal malformations in

288 the ETU-induced rat model of imperforate anus. Journal of Pediatric Surgery 37:1305-1312 DOI

289 10.1053/jpsu.2002.34996 
290 Rintala RJ. 2016. Congenital cloaca: Long-term follow-up results with emphasis on outcomes beyond

291 childhood. Seminars in Pediatric Surgery 25:112-116 DOI 10.1053/j.sempedsurg.2015.11.011

292 Tang XB, Zhang J, Wang WL, Yuan ZW, Bai YZ. 2014a. Spatiotemporal expression of Cdx4 in the developing 293 anorectum of rat embryos with ethylenethiourea-induced anorectal malformations. Cells Tissues Organs

294 199:212-220 DOI $\underline{10.1159 / 000365965}$

295 Tang XB, Zhang J, Wang WL, Yuan ZW, Bai YZ. 2016. The expression analysis of Bmpr1a and Bmp2 during 296 hindgut development in ratembryos with anorectal malformations. Experimental and Molecular

297 Pathology 101:143-149 DOI 10.1016/j.yexmp.2016.07.012

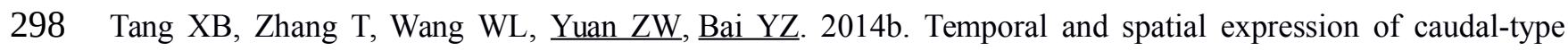
299 homeobox gene-2 during hindgut development in rat embryos with ethylenethiourea-induced anorectal

300 malformations. Cell and Tissue Research 357:83-90 DOI 10.1007/s00441-014-1858-0

301 Wang DJ, Bai YZ, Zhang SW, Gao H, Zhang SC, Zhang D, Zhang T, Yuan ZW, Wang WL. 2009. Expression 302 of EphB2 in the development of anorectal malformations in fetal rats. Journal of Pediatric Surgery 44:592-599

303 DOI 10.1016/j.jpedsurg.2008.08.017

304 Zhang J, Tang XB, Wang WL, Yuan ZW, Bai YZ. 2015. Spatiotemporal expression of BMP7 in the 305 development of anorectal malformations in fetal rats. International Journal of Clinical and Experimental

306 Pathology 8:3727-3734

307 Zhang T, Bai YZ, Wang dJ, 位 HM, Yuan ZW, Wang WL. 2009 Spatiotemporal pattern analysis of

308 transcription factor 4 in the developing anorectum of the rat embryo with anorectal malformations.

309 International Journal of Colorectal Disease 24:1039-1047 DOI 10.1007/s00384-009-0705-3

310 Zhao T, Gan Q, Stokes A, Lassiter RN, Wang Y, Chan J, Han JX, Pleasure DE, Epstein JA, Zhou CJ. 2014. $\beta$ -

311 catenin regulates Pax3 and Cdx2 for caudal neural tube closure and elongation. Development 141:148-157 DOI

$312 \quad 10.1242 /$ dev.101550

313 
Figure 1

Immunohistochemical analysis of Wif1 protein on GD 13

Fig. 1 Immunohistochemical analysis of Wif1 protein on GD 13. a, b Normal group.

On GD13, Wif1-immunopositive cells were extensively expressed on the epithelium and mesenchyme of the cloaca. c, d ARM group. On GD13, Wif1-labeled cells were extensively expressed on the epithelium and mesenchyme of the cloaca. (CM cloacal membrane, $\mathrm{H}$ hindgut, $U$ urethra, URS urorectal septum). Scale bar $=100 \mu \mathrm{m}$ in $\mathrm{a}, \mathrm{c} ;=50 \mu \mathrm{m}$ in b,d. Yellow rectangles in $\mathbf{a}, \mathbf{c}$ are shown at higher magnification in b, d. Original magnification: $\times 100(\mathbf{a}$, c), $\times 200(\mathbf{b}, \mathbf{d})$. Yellow arrows in $\mathbf{b}$ and $\mathbf{d}$ indicate positive expression of Wif1protein.
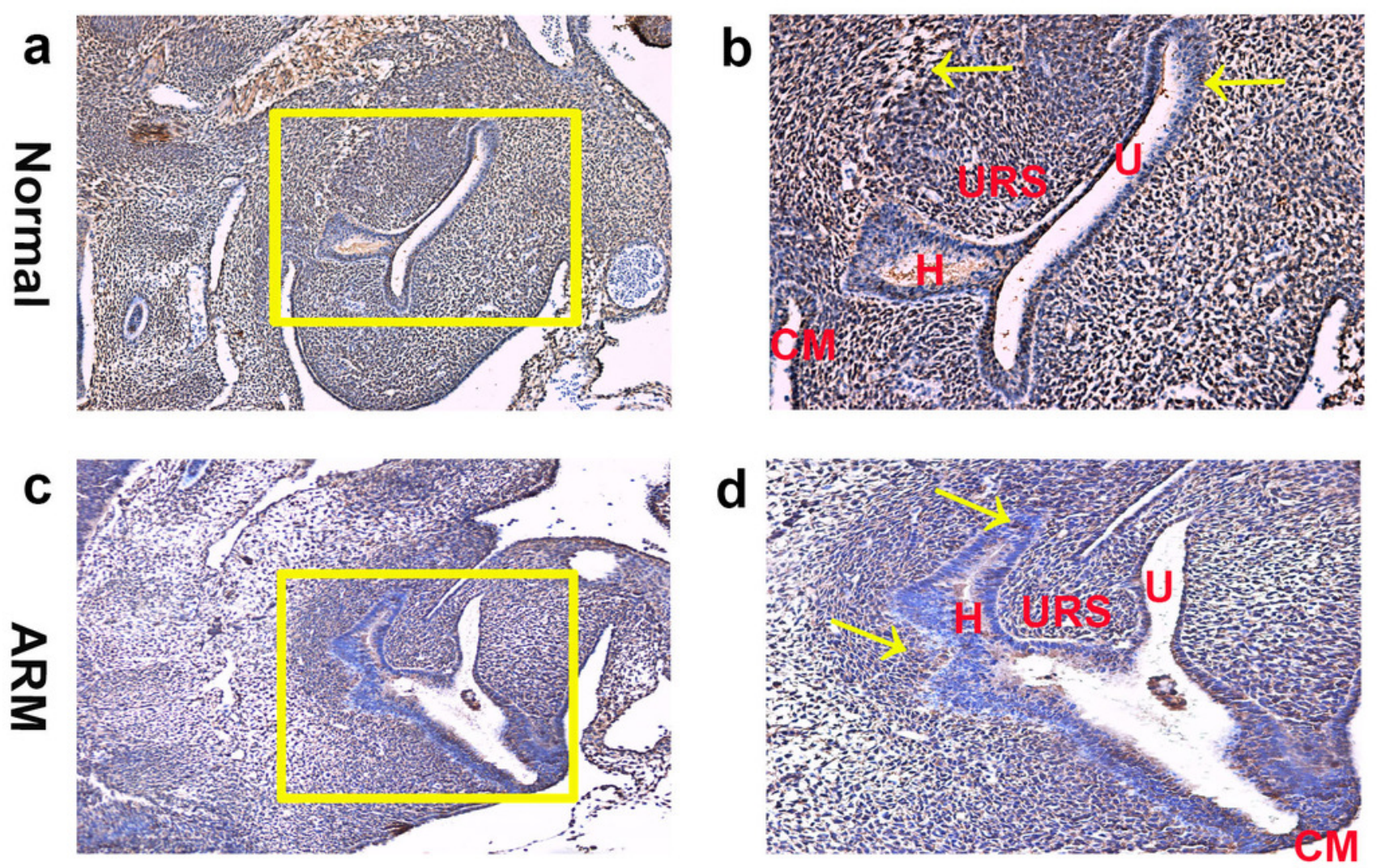


\section{Figure 2}

Immunohistochemical analysis of Wif1 protein on GD 14

Fig. 2 Immunohistochemical analysis of Wif1 protein on GD 14. a, b Normal group.

On GD14, Wif1-immunopositive cells were detected on the hindgut, urorectal septum, urethra and cloacal membrane. c, d ARM group. On GD14, Wif1 was faintly expressed on the epithelium of the hindgut, urorectal septum and the urethra. (CM cloacal membrane, $\mathrm{H}$ hindgut, U urethra, URS urorectal septum). Scale bar $=100 \mu \mathrm{m}$ in $\mathrm{a}, \mathrm{c} ;=25 \mu \mathrm{m}$ in b,d. Yellow rectangles in a, c are shown at higher magnification in b, d. Original magnification: $\times 100(\mathbf{a}$, c), $\times 400(\mathbf{b}, \mathbf{d})$. Yellow arrows in $\mathbf{b}$ and $\mathbf{d}$ indicate positive expression of Wif1protein.
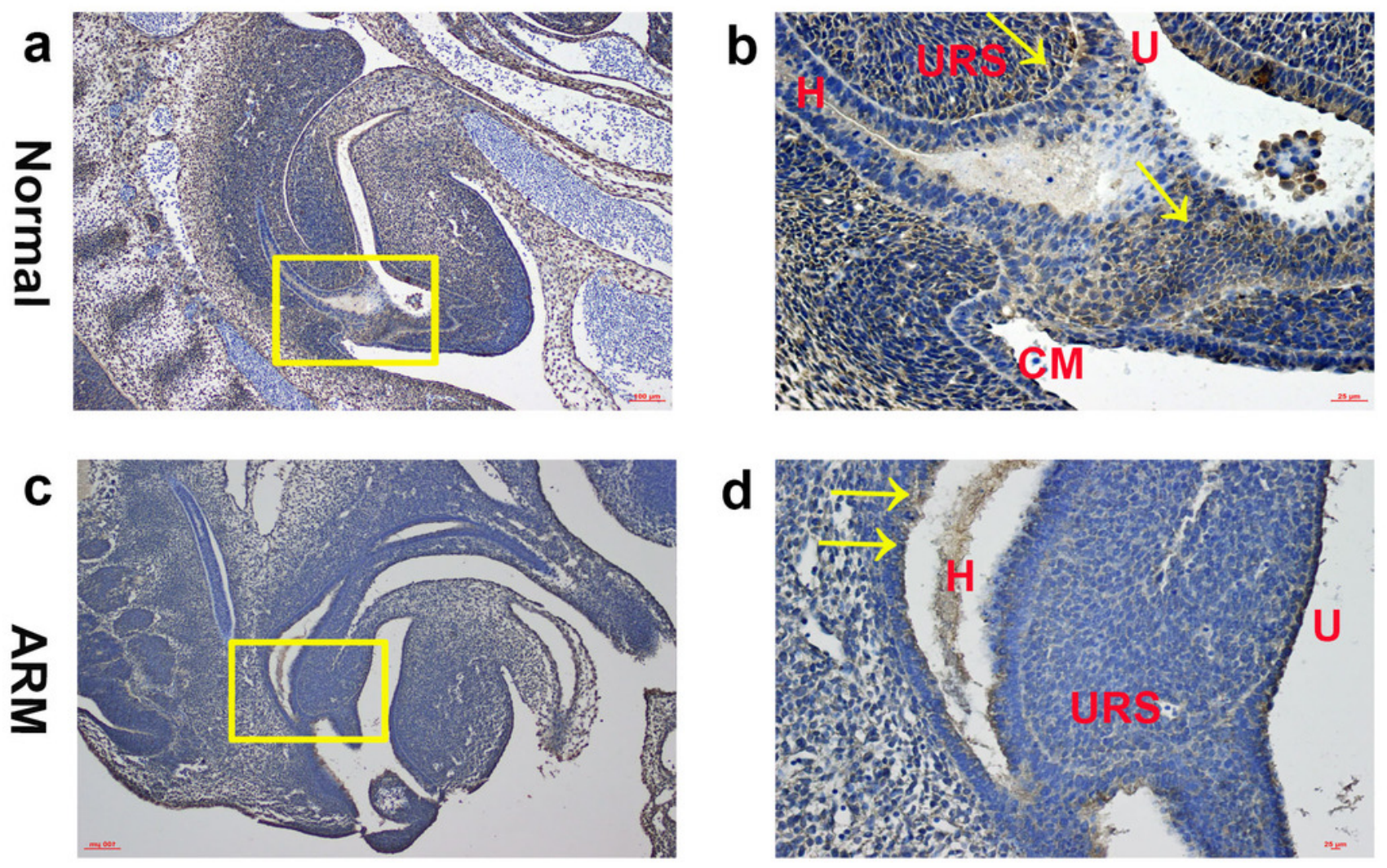


\section{Figure 3}

Immunohistochemical analysis of Wif1 protein on GD 15

Fig. 3 Immunohistochemical analysis of Wif1 protein on GD 15. a, b Normal group. On GD15, Wif1-immunopositive cells were mainly detected on the very thin anal membrane. c, d ARM group. On GD15, Wif1-positive cells were sparsely located on the epithelium of the hindgut, fistula and the urethra. (AM anal membrane, F fistula, $\mathrm{H}$ hindgut, $\mathrm{U}$ urethra, URS urorectal septum). Scale bar $=100 \mu \mathrm{m}$ in $\mathrm{a}, \mathrm{c} ;=25 \mu \mathrm{m}$ in b,d. Yellow rectangles in $\mathbf{a}, \mathbf{c}$ are shown at higher magnification in $\mathbf{b}, \mathbf{d}$. Original magnification: $\times 100(\mathbf{a}, \mathbf{c}), \times 400(\mathbf{b}, \mathbf{d})$. Yellow arrows in $\mathbf{b}$ indicate positive expression of Wif1protein.

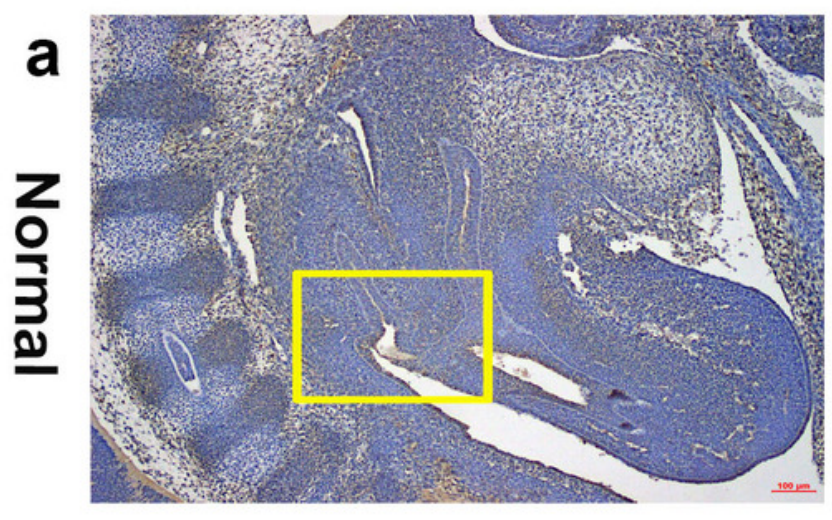

b
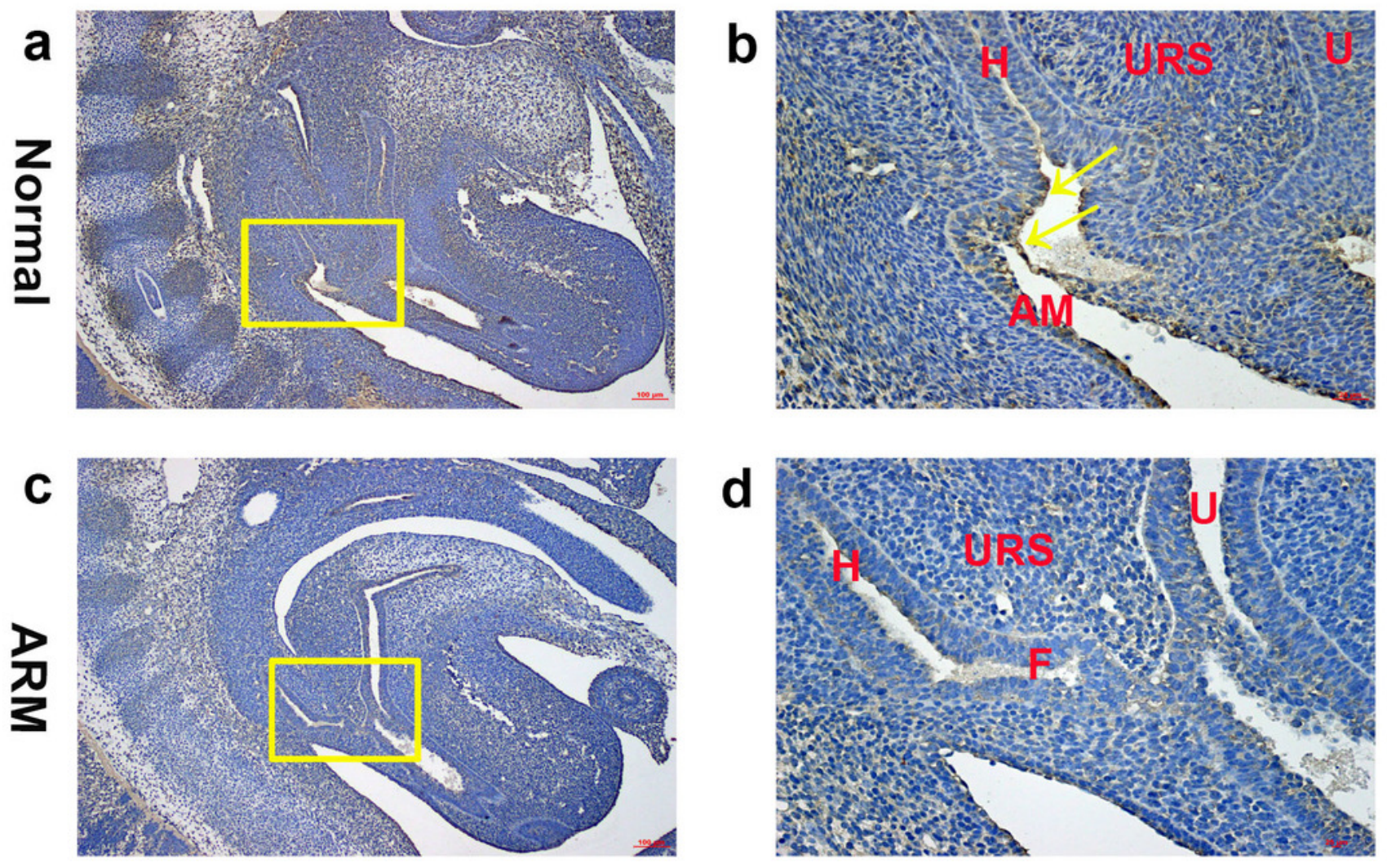

d

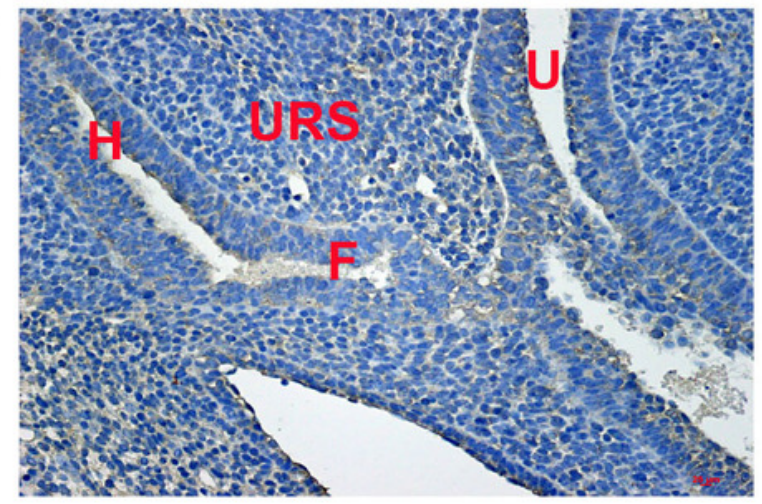




\section{Figure 4}

Immunohistochemical analysis of Wif1 protein on GD 16

Fig. 4 Immunohistochemical analysis of Wif1 protein on GD 16. a, b Normal group.

On GD16, Wif1-immunolabeled cells were observed on the epithelium of the distal anorectum. c, d ARM group. On GD16, Wif1 demonstrated low expression on the epithelium of the rectum, fistula and the urethra. ( $F$ fistula, $R$ rectum, $U$ urethra, URS urorectal septum). Scale bar $=250 \mu \mathrm{m}$ in $\mathrm{a}, \mathrm{c} ;=25 \mu \mathrm{m}$ in b,d. Yellow rectangles in $\mathbf{a}, \mathbf{c}$ are shown at higher magnification in b, d. Original magnification: $\times 40(\mathbf{a}, \mathbf{c}), \times 400(\mathbf{b}, \mathbf{d})$. Yellow arrows in $\mathbf{b}$ indicate positive expression of Wif1protein.

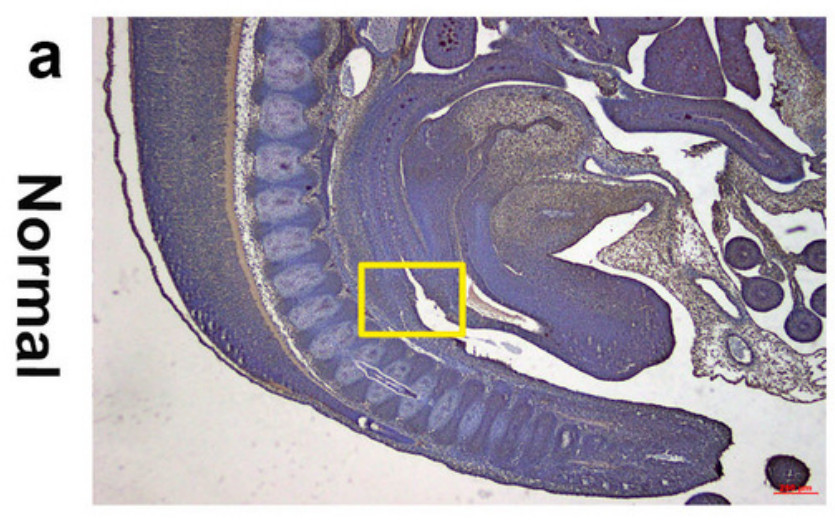

b
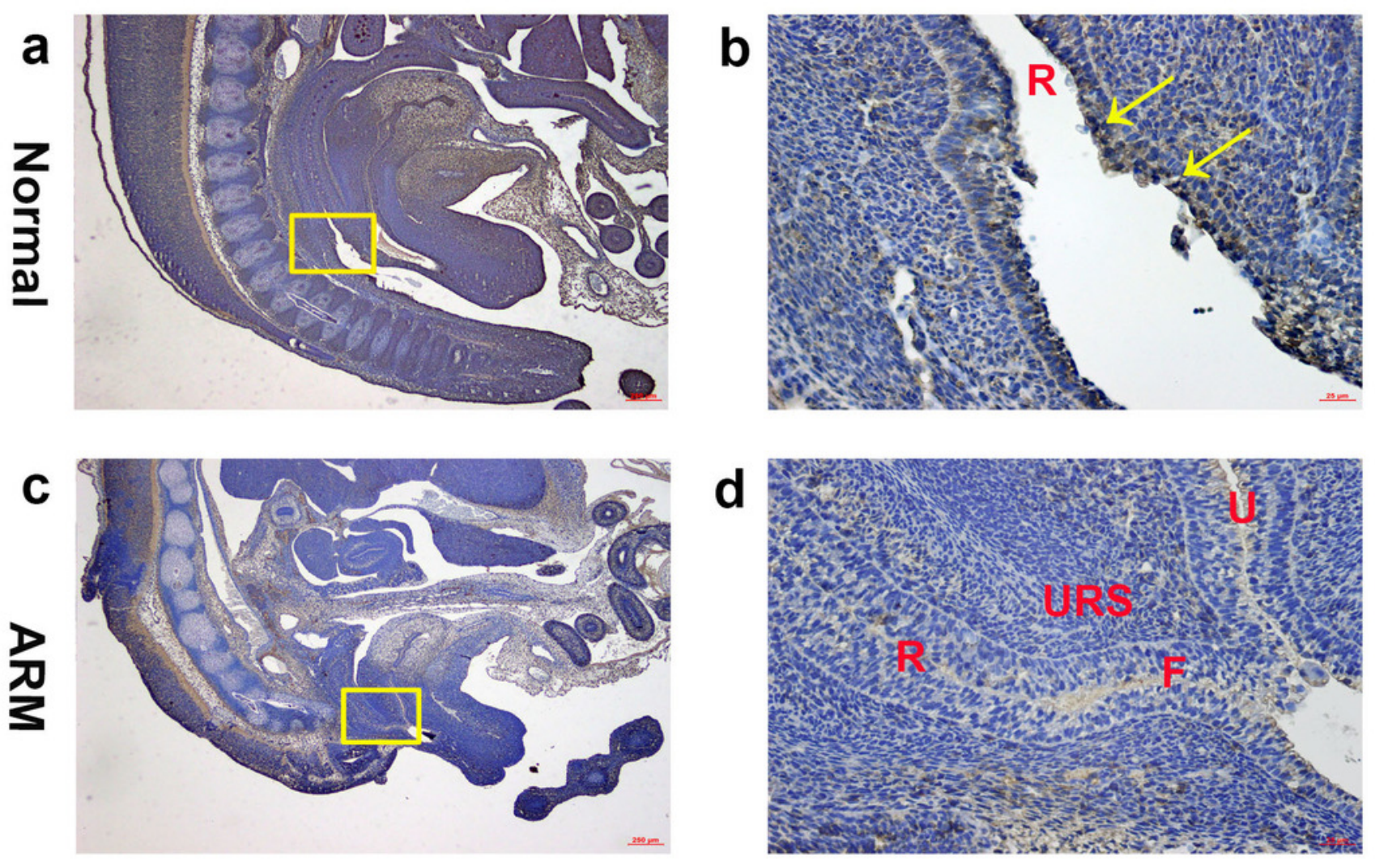

d

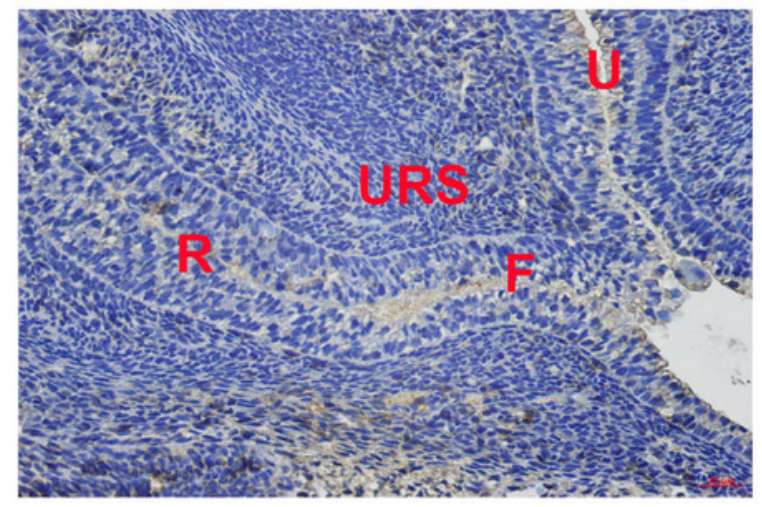




\section{Figure 5}

Western blot analysis of Wif1 and $\beta$-catenin protein

Fig. 5 Western blot analysis of Wif1 and $\beta$-catenin protein expression levels in normal and ARM developing hindgut tissue samples. Values are presented as means \pm SD. A. Wif1 and $\beta$-catenin was detected as bands of approximately $41-k D a$ and 95 kDa respectively. $\beta$-Actin protein is used as an internal control. B, C. Histogram showing the trends of Wif1 and $\beta$ catenin expression at each time-point. A peak can be noted on GD14 and GD15, by Tow Way ANOVA and post hoc test.

\section{$\begin{array}{lllllll}\text { N13 } & \text { N14 } & \text { N15 } & \text { N16 } & \text { A16 } & \text { A15 } & \text { A14 } \\ \text { A13 }\end{array}$}

A
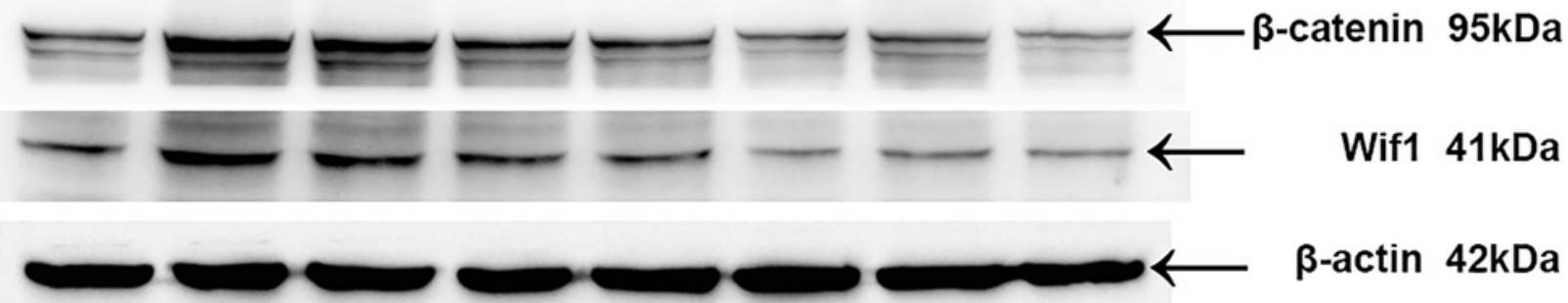

B

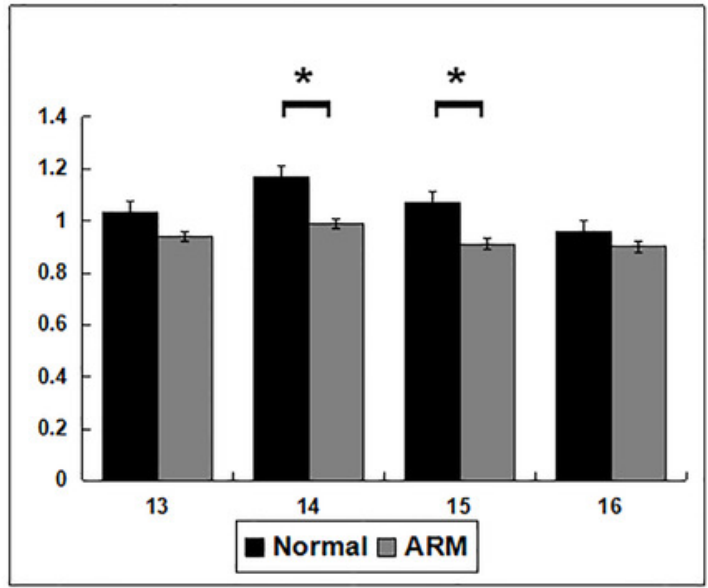

Wif1 protein expression level
C

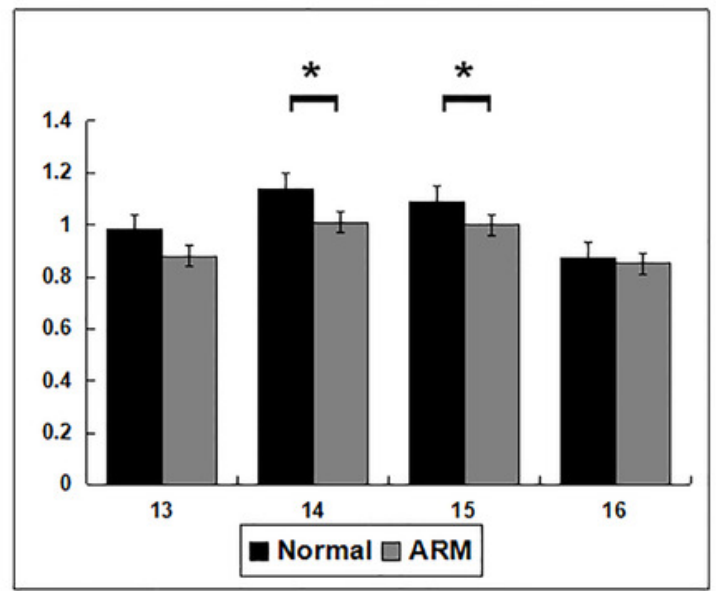

$\beta$-catenin protein expression level 


\section{Figure 6}

Real-time RT-PCR analysis of Wif1 and $\beta$-catenin mRNA

Fig. 6 Real-time RT-PCR analysis of Wif1 and $\beta$-catenin mRNA expression levels in normal and ARM-developing hindgut tissue samples. On GD14 and GD15, the key period of anus formation, Wif1 and $\beta$-catenin expression reaches the estimated optimum levels in the normal group, whereas in the ARM group, Wif1 and $\beta$-catenin mRNA is minimally expressed.Values are presented as means \pm SD. * Significant difference from corresponding controls, by Tow Way ANOVA and post hoc test.
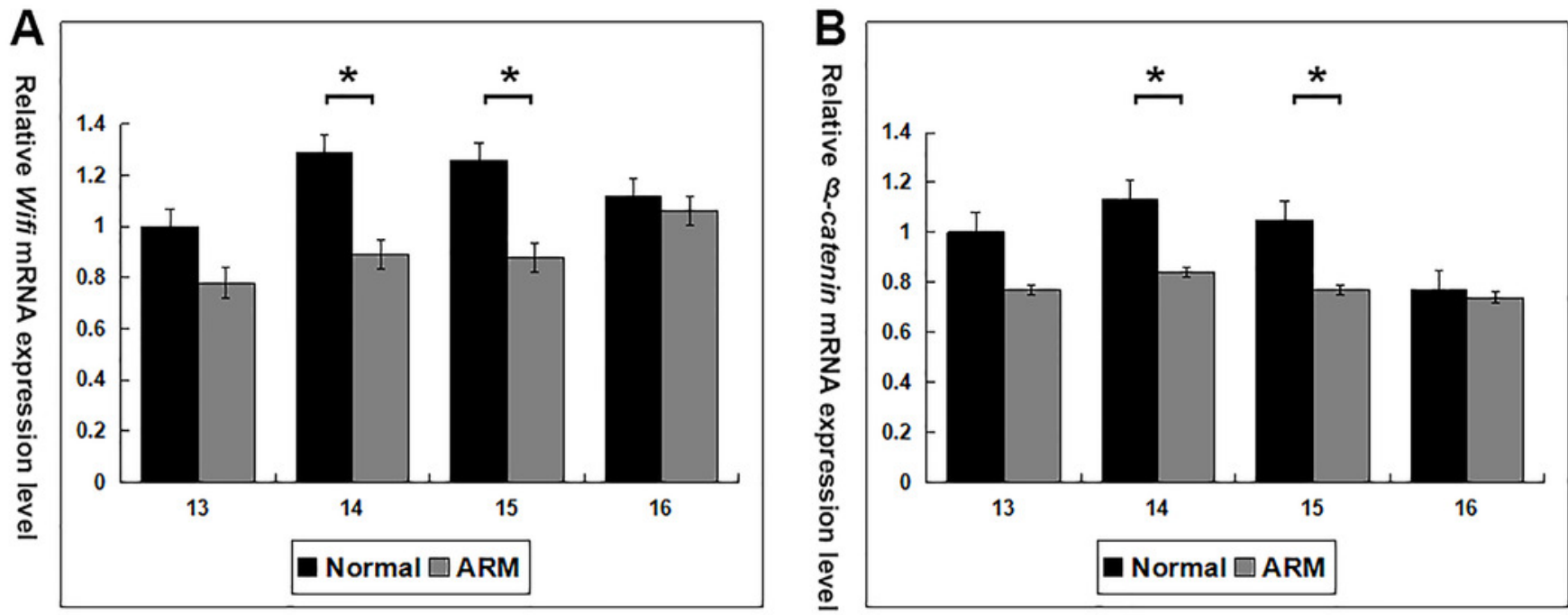


\section{Table $\mathbf{1}$ (on next page)}

Distribution of embryos in the various age and treatment groups. 
Table. 1 Distribution of embryos in the various age and treatment groups.

\begin{tabular}{lccccccc}
\hline Age & \multicolumn{3}{c}{ Normal } & & & \multicolumn{3}{c}{ ARMs } \\
\cline { 2 - 4 } \cline { 6 - 8 } group & IHC & WB & PCR & & IHC & WB & PCR \\
\hline GD13 & 25 & 26 & 27 & & 30 & 27 & 28 \\
GD14 & 24 & 25 & 26 & & 29 & 26 & 27 \\
GD15 & 22 & 25 & 25 & & 24 & 25 & 25 \\
GD16 & 20 & 22 & 21 & & 21 & 23 & 21 \\
Total & 91 & 98 & 99 & & 104 & 101 & 101 \\
\hline
\end{tabular}

ARMs anorectal malformations, GD gestational day, IHC immunohistochemical staining, WB

Western blot, PCR real time RT-PCR. 